\title{
A Framework to Support Multiple Perspectives in Eco-efficiency Decisions
}

\author{
Richard Farr ${ }^{1}$, Husam Arman ${ }^{1}$ and Nabil Gindy ${ }^{1}$ \\ ${ }^{1}$ University of Nottingham, UK
}

\begin{abstract}
Increasingly, it is recognised that human activity is causing our environment to degrade, and that there is a very real danger of doing irreversible damage to natural systems of which we have only a partial understanding. Neither living in, nor doing business in a future world with a degraded environment is desirable, and individuals and businesses alike are increasingly seeking ways to operate on a more sustainable basis.

Sustainability was defined by WCED [1] as "meeting the needs of the present without compromising the ability of future generations to meet their own needs" - but how can this aspiration be translated into specific decisions and actions? This paper describes some of the difficulties that must be overcome in the creation of a decision-support framework for eco-efficiency decisions, in order to ensure that we are targeting the right problems.
\end{abstract}

Key words: Sustainability, measurement, eco-efficiency, green manufacturing

\section{CONTEXT FOR ENVIRONMENTAL ISSUES}

In trying to make informed decisions about the environment, we have to remember that this is just one way in which an organisation or society can be measured, and that economic and social issues are equally important. Elkington [2] introduced this concept, now adopted in a standard for community accounting and often referred to as "people, planet, profit."

Before we can resolve the problems of the environmental dimension, we need to understand the economic and social drivers that have also shaped the present situation. Only by finding solutions that are viable from all three viewpoints can we hope to have those solutions adopted. Whatever else we might achieve, we cannot hope to 'put the genie back in the bottle'; despite the environmental harm that industrialisation has caused, it has also been instrumental in improving the lot of 
mankind. In 'The Wealth of Nations', Adam Smith [3] presented "improvement" (the cultivation of land and the establishment of industry) as desirable and logical, when compared with the life of a hunter-gatherer (which he described as "the lowest and rudest state of society").

Few people would wish for a return to that lowest state of society, nor even to life without electricity, anaesthetics or similar benefits. In any event, the question is effectively moot because an unindustrialised world could not support the current population of 6.8 billion. There is a danger that changes to our present strategy will result in famine - but we must also recognize that the present strategy is not sustainable. As Hoyle [4] described, social organisation tends to increase productivity, but productivity also tends to increase social organisation. This positive feedback system has led to tremendous progress, having its roots in the advances in agriculture at the end of the last glacial period and accelerating steadily until the beginning of the boom that we call the Industrial Revolution. It is no accident that population growth has accompanied these advances in wealth, but we now find ourselves in a world where we are consuming resources at an unprecedented rate, while attempting to meet the needs and wants of a growing and increasingly demanding population. As early as 1977, Hoyle [4] foresaw disaster.

Some people, businesses and governments have expressed a desire to improve their 'green' performance, but they struggle to identify the best solutions. In the absence of a holistic understanding of the various modes of environmental harm, some 'solutions' have themselves introduced new problems. For example, lowenergy light bulbs pose a hazard at end-of-life because they contain mercury; leadfree solder requires significantly higher processing temperatures (i.e. energy use in manufacture) and raises product reliability concerns; and the HCFC-22 gas that replaced ozone-damaging chlorofluorocarbons must itself be replaced because it is a potent greenhouse gas.

If we seek to address only one problem at a time, we cannot hope to reverse environmental degradation. Indeed, focusing on a single issue is a tactic often used by interest groups such as industry lobbyists. For example, a series of reports from CNW [5] have caused a storm of criticism for their assertion that a Toyota Prius is far less 'green' than a much larger Hummer. (CNW's study measures the expected useful life of a vehicle, the energy consumed during its manufacture, requirements for spares, and fuel used per mile. Criticism of the Prius centred upon its batteries, which are made from nickel mined in Canada, shipped to Wales for refining, then on to China and finally completed in Japan.) Advocates of the hybrid car have been quick to protest, and in fact there has been some very questionable science on both sides of the argument, including obvious inconsistencies and a lack of peer review. Meanwhile, perhaps the best answer for sustainability in motoring - that people should keep their current vehicle for longer, regardless of make and model - is very seldom heard. Naturally, it has no backing from manufacturers, and is not a 'glamorous' solution that is likely to receive interest from the press.

\section{DIFFICULTIES IN ESTABLISHING A MEASURE OF ENVIRONMENTAL HARM}

The debate about which products and solutions are truly 'green' will no doubt continue for many years to come. Regardless of the truth, the question raised about 
a hybrid car and its batteries provides a useful starting point. It shows that until we are able to consider the whole life of a product, we cannot be certain that any particular choice offers a more or less sustainable solution than any alternative. The CNW report [5] will always be open to criticism because it focuses upon cost per mile, and does not address the full spectrum of environmental, social and economic issues.

Some research aims to address a broader range of factors. For example, the 'ecological footprint' calculations of Wackernagel et al [6] attempt to evaluate the lifestyle of a person or household in terms of the 'number of Earths' that would be required to sustain us (more accurately, the number of years that would be required to regenerate what humanity uses per year). This concept of biosphere capacity has come to the attention of policymakers, and also the public. It can be found, for example, in the web-based assessment offered by the Centre For Sustainable Economy [7]. This presents a review of four consumption categories: carbon (for home energy use and transportation), food, housing, and goods and services. The unit of measure is 'global hectares', reflecting the amount of land required to make consumption sustainable. Some conversions are necessary, of course, since not all resources are renewable on a human timescale (such as the depletion of coalmines and oil wells). We can, however, measure the amount of land required to absorb a given amount of $\mathrm{CO}_{2}$ or the size of biomass plantation required to provide an equivalent amount of energy.

The concept of the 'carbon footprint' is well established, but again, this is a simplistic measure of environmental harm. $\mathrm{CO}_{2}$ is merely the most abundant greenhouse gas; the Intergovernmental Panel on Climate Change studies seventeen others [8]. As a means of understanding the relative levels of harm from a variety of emissions, the less well-known equivalent tonnes of carbon dioxide $\left(\mathrm{CO}_{2} \mathrm{e}\right)$ and carbon dioxide equivalent (CDE) measures allow some comparisons to be made. Even so, these fail to take into account many other environmental issues such as watercourse contamination, local air quality, acid rain, resource depletion, ozone layer damage, habitat destruction and others.

When attempting to minimize environmental harm, we must recognize that different communities are faced with different problems. Where poverty still kills far more people than pollution, a higher level of pollution is going to be tolerated. Where a resource is abundant - at least for now - it will not be conserved with care. Within a holistic model containing environmental, social and economic drivers, the value of each entity can be expected to vary, over time. As we strive to reduce the rate of climate change (in the hope of limiting the average global temperature rise to a maximum $2^{\circ} \mathrm{C}$, perhaps) preventing the emission of a tonne of $\mathrm{CO}_{2}$ during 2010 will be worth far more to us than preventing the emission of an equal quantity of the same gas in 2040, because a tonne of $\mathrm{CO}_{2}$ emitted in 2010 will have had an influence in all of the intervening thirty years.

We also have the problem of choosing between alternative modes of environmental harm, which act over different timescales. For example, where the construction of a wind farm presents a hazard to migrating birds, what value do we place on those creatures? If the alternative is a fossil fuel energy source, might that not pose a greater threat? How much do we value the life of an orangutan, if replacing the 
natural forest with a palm oil plantation offers employment, economic activity and (arguably) renewable resources? What value will we place upon the last orangutans? This is a valid question, with Nellemann et al [9] reporting a $91 \%$ reduction in animal numbers, accelerating towards the end of the $20^{\text {th }}$ century. So how many of each species constitutes 'enough' - and do we have the right to decide?

Even human life has a variable price, as we can see from the compensation paid after an accident occurs or a health problem arises, varying from one country to another, even for employees of the same multinational. We also have a morass of psychological issues to take into account when considering risks to human beings. For example, Fischlowitz-Roberts [10] reports that 70,000 people die in the USA every year as a result of air pollution, yet we have become inured to this annual death toll. Although it is clear that industry, power generation and traffic all play a role, it will be very difficult to separate out the various sources of harm and set reduction targets for each.

By contrast, $\mathrm{CO}_{2}$ is effectively harmless at the point of emission. It contributes to climate change [8] but it does so on a global basis, and over a very long period of time. Looking for evidence of degradation in our environment requires the study of changes that are quite literally glacial. As such, there is a danger that ordinary people and policymakers alike will decide that there are more pressing concerns, and that greenhouse gases are somebody else's problem. In this, we re-enact Hardin's [11] 'Tragedy of the Commons'; that although acting rationally and in self-interest, we will produce a long-term result that is not in our best interest.

Hardin's [11] original 'commons' was a pasture that suffered over-grazing; the new common resource is the atmosphere, and its capacity to accommodate a certain amount of greenhouse gases. This is in contrast to the more local forms of pollution (soil, watercourse, etc.), which have no appreciable effect in other nations; a fact that might make offshoring and outsourcing strategies attractive to businesses that face stringent pollution laws at home. Developing nations that have participated in the new, globalised manufacturing paradigm have benefited economically, but at great cost, finding themselves in some cases in a 'race to the bottom', not only economically but also morally, to the detriment of local communities and ecology.

There is a clear need for a model or framework that allows us to investigate the environmental, social and economic consequences of a decision. That decision might be one of legislation, of product design, of business strategy, of the selection of a source of supply, etc.; we need a system of 'green calculus' that allows informed decisions to be made, taking into account a broad range of consequences, acting on different timescales. Only then can we support the difficult decisions that mankind faces in the years ahead.

\section{A FRAMEWORK FOR ENVIRONMENTAL ASPIRATIONS}

Thus far, we have seen that there exist a variety of issues that might be considered under the umbrella of 'eco-efficiency', and that they will each have a different degree of importance when considered by a particular group. The perspective of a community, a government, an interest group or a particular industry will influence the environmental goals that are set. For example, saving water might be of prime 
importance in sub-Saharan Africa, while being a trivial issue in Canada. Such discrepancies must be reflected in any models that are created, and we can accommodate this within a common framework via a weighted multi-criteria profile. While we cannot know the weighting that each issue will have, it is possible to begin formulating a set of eco-efficiency goals, to be prioritized via pair-wise comparison or a similar method. An initial set of issues were gathered via literature survey, taking into account descriptions of environmental problems, proposed technological solutions and legislation such as EU Directives.

The findings of a sustainable manufacturing workshop that was held at the University of Nottingham in July 2009 [12] emphasise and reinforce these needs. A group of 24 delegates from industry and academia, active in the area of sustainability, used a technology roadmapping methodology to identify and prioritise a number of ecoefficiency considerations that have since been incorporated into our framework. (One of the most significant requirements of our opinion leaders was to differentiate between present-day 'green' aspirations and the needs of the longer term, i.e. 2050+.) Another excellent source for generic issues was the UK's Department for Environment, Food and Rural Affairs. DEFRA has grouped environmental concerns into a number of thematic areas, including food supply, animal welfare, climate change, resource efficiency, air quality, local environment (noise, litter, etc.) radioactive substances, land management (including biodiversity), water supply (including flood risk and coastal erosion) and the marine environment [13]. It is encouraging to see all these issues being addressed by a single body, because our choices necessarily reflect a compromise. Resources are limited, and in some cases we must choose what aspects of the people/planet/profit system to protect.

Saunier [14] concurs, describing sustainable development as having four components, namely human development, nature conservation, natural resources management and environmental protection. With this kind of trade-off in mind, we need to find ways to improve our performance against selected targets while remaining aware of the risks of degrading our performance elsewhere. Within the framework that we seek to create, trade-offs of this kind will be mediated by a computer-based decision support system that makes use of a standardized framework for 'green' or even 'triple bottom line' accounting. As we have seen, this is by no means simple, because the cost or value of each component (tonne of $\mathrm{CO}_{2}$ emitted, hectare of wilderness, barrel of oil, etc.) within the global system will vary over time, and from place to place. We handle this problem by inviting users to apply weightings to a standard set of issues, reflecting their relative importance.

Imagine being faced with a choice between a product that requires a large quantity of energy during manufacture, an alternative that is simpler to make but has a shorter life expectancy, a third that will require more consumables during operation, and a fourth that contains a certain quantity of cadmium and lead. Each poses different problems that can only be evaluated if their whole life cycle is understood in-depth, including the 'failure modes' by which they cause environmental harm. To some extent, legislation can eliminate dilemmas of this kind, but this simply transfers the problem to the policymakers, who must anticipate the problems posed by each material and technology. Legislation will always be something of a blunt instrument where some issues (e.g. $\mathrm{CO}_{2}$ ) have a global impact, while others are local in nature. 
Calculations of total environmental harm can be performed, following a product from 'cradle to grave' and measuring the total environmental impact, but the results will always depend upon what is felt to be of value. For example, in a study looking at disposable and reusable nappies, Hailes [15] concludes, "You have to decide whether you're more concerned about waste, in which case you'd choose reusables, or climate change, in which case you'd go for disposables." Our proposed system copes well with dilemmas of this kind, since a weighted profile ensures that it will reflect the values of the decision-makers.

It is also important that we should be able to perform these calculations rapidly. Instead of trying to improve the 'green' performance of individual products and processes once a design has been completed, we need to be able to choose between conceptual product/service systems at an early stage. We anticipate that calculations will be based upon responses to a series of generic questions, much like those seen in the Lucas Engineering design for assembly analysis [16]. While the penalties that are accrued in such systems are necessarily an abstraction, they will still permit a choice between alternatives, where the lowest-scoring solution ought to be the most efficient, once taken through the detailed product development process.

Our decision-support framework will be the subject of a two-year project, due to begin in November 2009. With work conducted concurrently in China, Malaysia and the UK, it is intended to show how eco-efficiency goals can vary from one country to another, yet still be encapsulated within a single model, reflecting the globalised nature of modern trade. Figure 1 shows an overview of the proposed framework. It begins with a strategic layer where the competing eco-efficiency goals are resolved via a system of weightings, and these aspirations are fed into the second phase. 


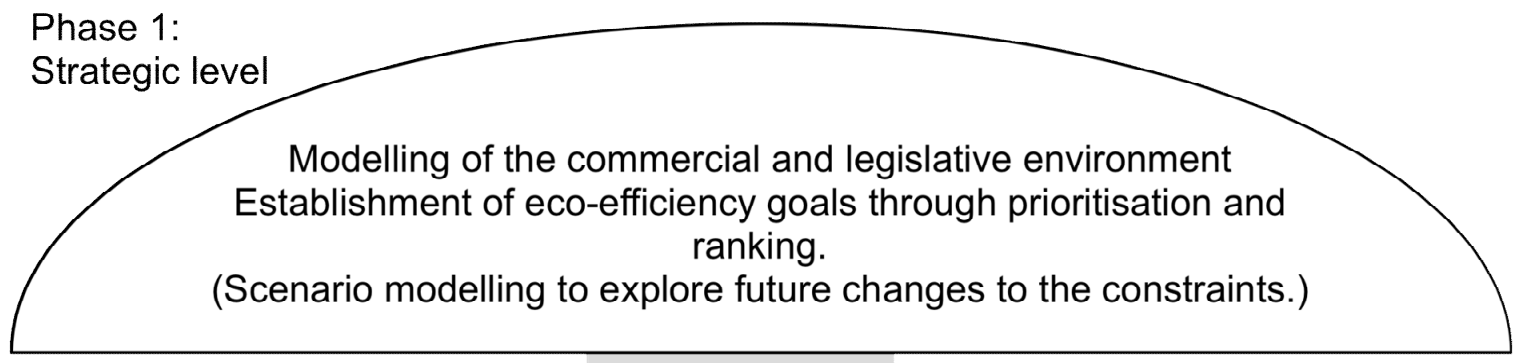

Phase 2: Generation of conceptual solutions

\begin{tabular}{|ll|l|}
\hline $\begin{array}{l}\text { Technology } \\
\text { selection within } \\
\text { product concepts }\end{array}$ & Modular & $\begin{array}{l}\text { Business model and } \\
\text { partitioning of } \\
\text { product concepts }\end{array}$ \\
\end{tabular}

Phase 3: Detailed design support tools

Eco-advisor
for electro-
mechanical
products

Eco-advisor
for
automotive
systems
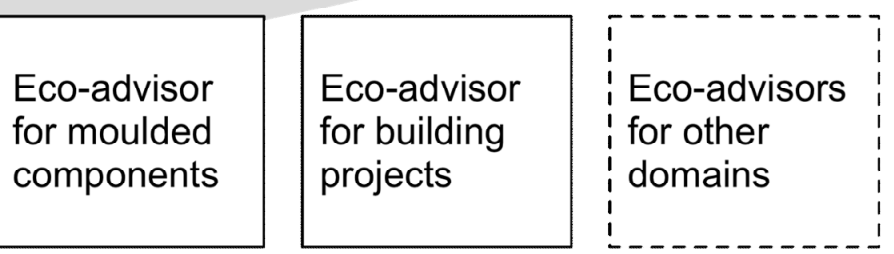

Figure 1: Three-layer architecture of the proposed framework

Conceptual solutions are addressed within the second layer of the framework, where key product characteristics such as energy consumption or anticipated useful life can be compared against the goals expressed in the first phase. At this stage, we also examine the eco-efficiency of any services that are being 'designed in', such as planned performance restoration or mid-life upgrades of the kind that are seen in the aerospace industry. The final layer of the framework consists of a series of tools to promote eco-efficiency during the detailed design stage. These tools are industryspecific, with modules reflecting the interests of the project consortium.

\section{CONCLUSIONS}

Improving the eco-efficiency of all our operations is going to be vital, if our quality of life is not to reduce sharply during the $21^{\text {st }}$ century, yet some of the 'solutions' that have been tried have introduced new forms of problem (some examples of this kind were given in Section 1). To consider eco-efficiency within decision-making will require two things: an understanding of the full life cycle consequences of any decision (detailing all modes of environmental degradation), and an understanding of the outcomes that are of value to businesses and communities. Without these, we cannot help people to choose wisely.

The proposed decision support system will address these needs through the development of a common framework that helps various stakeholders - engineers, purchasing staff, entrepreneurs, legislators and citizens - to understand environmental harm, compliance with legislation and best practice, to facilitate the development of eco-friendly engineered products. 


\section{REFERENCES}

[1] World Commission on Environment and Development, WCED. (1987) Report to the General Assembly of the United Nations, 96th plenary meeting, 11 December 1987, A/RES/42/187

[2] Elkington, J. (1994), 'Towards the sustainable corporation: win-win-win business strategies for sustainable development', California Management Review, Vol. 36, No. 2

[3] Smith, A. (1776) 'An Inquiry into the Nature and Causes of the Wealth of Nations', W. Strahan and T. Cadell, London

[4] Hoyle, F. (1977) 'Ten faces of the universe', First Edition, W. H. Freeman, San Francisco. ISBN: 071670384X

[5] CNW Marketing Research (2000 - 2008), 'Dust to Dust Energy Report Automotive', available from http://www.cnwmr.com/

[6] Wackernagel, M., Schulz, B., Deumling, D., Callejas-Linares, A., Jenkins, M., Kapos, V., Monfreda, C., Loh, J., Myers, N. and Norgaard, R. (2002),'Tracking the ecological overshoot of the human economy', Proceedings of the National Academy of Sciences of the United States of America 99 (14), 9266-9271

[7] Centre for Sustainable Economy (2009) 'Ecological Footprint Quiz', available from http://www.myfootprint.org/

[8] Intergovernmental Panel on Climate Change, IPCC. (2007) 'Climate Change 2007 - The Physical Science Basis', Contribution of Working Group I to the Fourth Assessment Report of the IPCC, ISBN: 9780521 88009-1

[9] Nellemann, C., Miles, L., Kaltenborn, B.P., Virtue, M., and Ahlenius, H., editors (2007) 'The last stand of the orangutan - State of emergency: Illegal logging, fire and palm oil in Indonesia's national parks', United Nations Environment Programme, GRID-Arendal, Norway, ISBN: 978-82-7701-043-5

[10] Fischlowitz-Roberts, B. (2002) 'Air Pollution Fatalities Now Exceed Traffic Fatalities by 3 to 1', September 17 th 2002 , available from http://www.earthpolicy.org/Updates/Update17.htm

[11] Hardin, G. (1968) 'Tragedy of the Commons', Science, No. 162, pp. 12431248

[12] Anon (2009) 'Sustainable Manufacturing Workshop Results', University of Nottingham, July 2009, available from http://www.nottingham.ac.uk/csgm/ workshop.html 